\title{
Geographic Object-Based Image Analysis of Changes in Land Cover in the Coastal Zones of the Red River Delta (Vietnam)
}

\author{
Simona Niculescu, Chi Nguyen Lam \\ University of Western Brittany, CNRS, Brest, France \\ Email: simona.niculescu@univ-brest.fr
}

How to cite this paper: Niculescu, S. and Lam, C.N. (2019) Geographic Object-Based Image Analysis of Changes in Land Cover in the Coastal Zones of the Red River Delta (Vietnam). Journal of Environmental Protection, 10, 413-430.

https://doi.org/10.4236/jep.2019.103024

Received: December 31, 2018

Accepted: March 10, 2019

Published: March 13, 2019

Copyright $\odot 2019$ by author(s) and Scientific Research Publishing Inc. This work is licensed under the Creative Commons Attribution International License (CC BY 4.0).

http://creativecommons.org/licenses/by/4.0/

cC) (i) Open Access

\begin{abstract}
The majority of the population and economic activity of the northern half of Vietnam is clustered in the Red River Delta and about half of the country's rice production takes place here. There are significant problems associated with its geographical position and the intensive exploitation of resources by an overabundant population (population density of 962 inhabitants $/ \mathrm{km}^{2}$ ). Some thirty years after the economic liberalization and the opening of the country to international markets, agricultural land use patterns in the Red River Delta, particularly in the coastal area, have undergone many changes. Remote sensing is a particularly powerful tool in processing and providing spatial information for monitoring land use changes. The main methodological objective is to find a solution to process the many heterogeneous coastal land use parameters, so as to describe it in all its complexity, specifically by making use of the latest European satellite data (Sentinel-2). This complexity is due to local variations in ecological conditions, but also to anthropogenic factors that directly and indirectly influence land use dynamics. The methodological objective was to develop a new Geographic Object-based Image Analysis (GEOBIA) approach for mapping coastal areas using Sentinel-2 data and Landsat 8. By developing a new segmentation, accuracy measure, in this study was determined that segmentation accuracies decrease with increasing segmentation scales and that the negative impact of under-segmentation errors significantly increases at a large scale. An Estimation of Scale Parameter (ESP) tool was then used to determine the optimal segmentation parameter values. A popular machine learning algorithms (Random Forests-RFs) is used. For all classifications algorithm, an increase in overall accuracy was observed with the full synergistic combination of available data sets.
\end{abstract}

\section{Keywords}

Coastal Zones, Red River Delta, Land Cover Changes, Remote Sensing, 
Geographic Object-Based Images Analysis

\section{Introduction}

Coastal areas are subject to numerous pressures acting on a limited space. The current developments in the context, simultaneously climatic, economic and societal, make governance of changes in the coast areas land cover a fundamental issue. Land Use/Land Cover (LULC) is essential in planning and management activities especially for conserving the eco-environment as well as for urban planning in coastal areas. Nowadays, the use of remotely sensed data in order to produce a LULC map is rapidly increasing since it offers advantages in terms of cost effectiveness and accuracy [1]. Recently, apart from the availability of the Very High Resolution (VHR) European satellite imagery like Sentinel-2, the use of object-based method for extracting LULC is combined with VHR imagery to produce better results. The Sentinel-2 sensor (equipped with a multi-spectral instrument, MSI), launched on 23 June 2015 by the European Space Agency (ESA), provides a significant improvement in spectral coverage, spatial resolution, and temporal frequency over the current generation of Landsat sensors. For land cover/land use mapping Sentinel-2 is especially relevant for the presence of two new bands in the red edge spectrum, at 705 and $740 \mathrm{~nm}$.

The study site is a coastal sector of the Red River delta in Vietnam and the goal is to observe the changes in terms of the land cover of the coast zone. Some thirty years after the economic liberalization and the opening of the country to international markets, agricultural land use patterns in the Red River Delta, particularly in the coastal area, have undergone many changes. As a second phase, a change in land management took place within "Doi Moi" policy framework. A market economy has replaced the socialist economy. This policy, also known as "revival", was proclaimed in 1986 by the Government and the Vietnamese Communist Party to reform and renovate the political and economic field of the country.

This article discusses the implementation of Geographic object-based image analysis (GEOBIA) for coastal mapping of changes of land use in River Red Delta in Vietnam. This is both an opportunity and challenge for GEOBIA in the mapping and monitoring of land use. GEOBIA is a newly evolving sub-discipline of geographic information science (GIScience) devoted to partitioning remote sensing (RS) imagery into meaningful image-objects, and assessing their characteristics through spatial, spectral and temporal scale. At its most fundamental level, GEOBIA requires image segmentation, attribution, classification and the ability to query and link individual objects (a.k.a. segments) in space and time. Geographic object-based image analysis (GEOBIA) has been gaining prominence in the fields of remote sensing and GIScience over the past decade, especially for the processing of high spatial resolution imagery [2]. The emerging 
trends were found in multiple sub fields of GEOBIA, including data sources, image segmentation, object-based feature extraction, and geo-object-based modeling frameworks [3]. GEOBIA is strongly associated with the notion of image segmentation. Along with the advent of multi-sensor and higher spatial resolution data more research focused on image texture as well as contextual information that describes the association of neighboring pixel values and has been shown to improve image classification results [4] [5] [6]. GEOBIA is a "recent" approach (including theory, methods, and tools) to partition remote sensing imagery into meaningful image-objects, and assess their characteristics through scale. Its primary objective is the generation of geographic information (in GIS-ready format) from which new spatial knowledge or "geo-intelligence" [7] can be obtained. GEOBIA is an evolving paradigm with specific tools, software, methods, rules, and language and it is increasingly being used for studies that need to conceptualize and formalize knowledge representing location based reality [8]. The classification process of this method uses a hierarchical segmentation process at the pre-processing stage so that the object characteristics can be supplemented with additional information such as text, texture, context and other information related to the object. In this study, a new concept, a new data satellite and a new methodology are implemented. The novelty of the approach is methodological. The methodology proposed a two stage process of segmentation and then classification of created segments. The initial segmentation process strongly influences the classification accuracy. Generally is very difficult to obtain satisfying segmentation results using the same parameters for all objects of the images. Baatz et al. (2008) [9] described this method as a combination of a spiral model and a modular classification approach. In the spiral model, objects are repeatedly modified using various segmentation and classification algorithms, until they represent the real world entities, as proper as possible. With the progress of the spiral model many research observed an increase in the level of details and the accuracy of classification [10].

This paper describes new developments in data sources, image segmentation, object-based feature extraction, and geo-object-based modeling frameworks, followed by a discussion about opportunities for future research and conclusions.

\section{Study Site}

The majority of the population and economic activity of the northern half of Vietnam is clustered in the Red River Delta (Figure 1) and about half of the country's rice production takes place here.

There are significant problems associated with its geographical position and the intensive exploitation of resources by an overabundant population (population density of 962 inhabitants $/ \mathrm{km}^{2}$ ). Periodic floods threaten an agricultural activity with an accelerating yield, which weakens the environment. Food production in the delta is mainly based on the rice harvest during the second half of the 


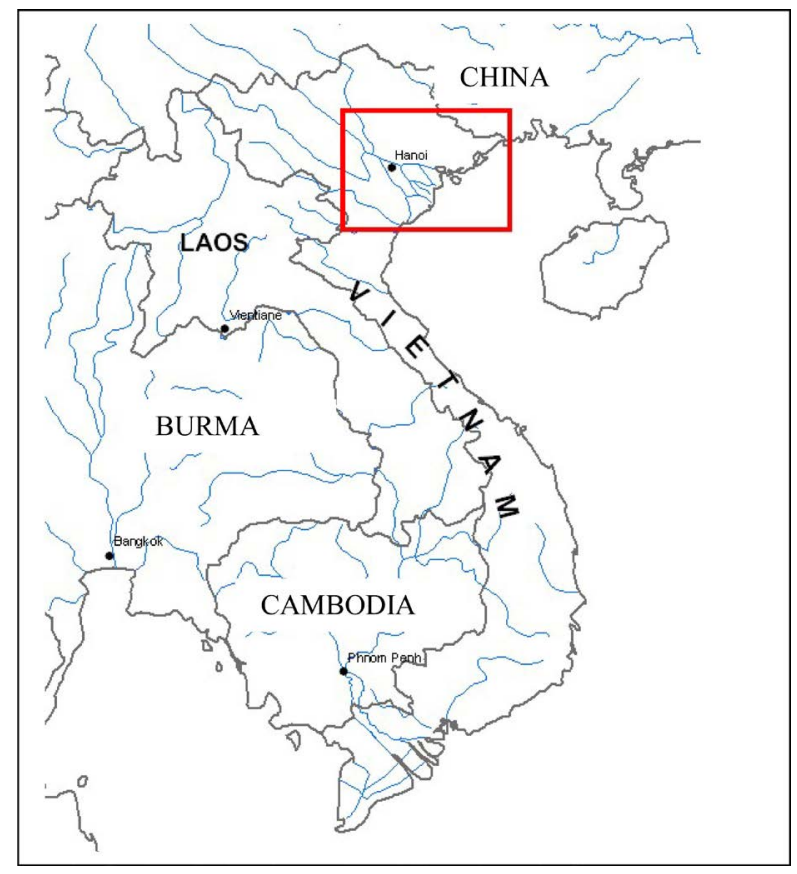

Figure 1. The red river delta and its coastal zone.

year. This is very often preceded by periodic flooding that threatens economic activities in general and agricultural activities in particular. The country's recent transition to a market economy has resulted in increased yields following intensified agricultural activities which led to greater environmental vulnerability. After some forty years of economic liberalization and the opening of the country to international markets, agricultural land use patterns in the Red River Delta, and particularly in the coastal areas, have undergone many changes.

The production and marketing of aquaculture products in the coastal areas of Vietnam are very significant economic issues as they have allowed, and still allow, a rapid improvement in the income levels of the local population. This includes peasants and fishermen who rely heavily on the natural resources of the coastal zone to increase production. Mangroves and even rice paddies are being replaced by aquaculture fields at an unprecedented pace [11]. These land use changes, which mean that increasingly larger areas are taken over by aquaculture ponds, have unfortunately contributed to a decline in mangrove forests. Since the latter is a protective component in the coastal zone, water pollution due to effluents of waste products discharged from livestock plots, has increased. The natural resources of this environment are under extreme threat due to intensive exploitation. All of these problems necessitate land-use planning by studying the country's economic and political changes in order to find sustainable crops or to protect the environment in the coastal region of the delta.

Current land use in the coastal area is farming, with rice as the main crop. Two rice crops and one dry crop is produced per year [12]: sweet potatoes, potatoes, peanuts, tobacco, corn, etc. In some very low-lying, salty and recently cleared areas, bulrush is temporarily grown to improve the soil quality before 
giving way to rice crops. On the contrary, the residential areas are located on higher land out of reach of floods. Here were find villages where there are alternating orchards and shade trees such as banana, eucalyptus and filao, as well as some fruit trees. In saline coastal areas and estuaries, vegetation naturally develops to form forests. However, the predominant plant formation is mangrove forest, mainly of the type Sonneratia, with a height ranging from 1 to $3.5 \mathrm{~m}$. A significant part of this area is currently covered by aquaculture ponds for the cultivation of shrimp and crab, using industrial as well as traditional methods. In some high-lying areas, filao is grown for the production of wood and for the protection of villages in the interior against storms.

\section{Land Management in the Delta of the Red River}

As a second phase, a change in land management took place within "Doi Moi" policy framework. A market economy has replaced the socialist economy. One year later (in April 1988), the so-called "khoan 10" decree no. 10 was adopted by the Political Bureau, marking a clear shift in economic orientation and a broad liberalization of private trade. Some fundamental points: Farmers obtained property rights to their land. Even though the State retains ownership of the land, private use thereof was permitted. Farmers were therefore granted land rights when the state planning system was abolished. Taxes paid by the farmers to the State were reduced to $10 \%$ and this rate remained unchanged for 5 years (this term was previously one year), which provided reassurance to farmers regarding the sustainability of their operations. The principle of egalitarian allocation of farmland was abandoned. Instead, these were allocated according to the farmers' production capacity and the availability of cooperative land. The term of lease for rice paddies, previously set at between 1 and 3 years, was increased to 20 years. The "simplified package" was replaced by the "net package", which allowed farmers to be responsible for 8 stages of rice growing, instead of the 5 stages traditionally granted. The majority of agricultural taxes were reduced (lower prices for chemical fertilizers, insecticides and fuel, the abolition of progressive taxes and other taxes levied by local authorities such as income tax or solidarity tax) which allowed farmers to reduce their operating costs. Farmers were then also allowed to sell their harvested produce on a free market, without working through a cooperative, as the household has since been considered an independent economic unit, and each farmer was therefore able to benefit from his own harvest. This decree has been enforced in the south of Vietnam since 1988. It only entered into force in the north of the country two years later, where conservative leaders, seeking to retain their power and privileges, opposed all forms of land management reforms.

\section{Data Set and Rice Cultivation Schedule}

In this article, we used Sentinel-2 optical satellite data and optical Landsat- 8 data (Table 1). 
In this study the main data source originate from the Sentinel-1 satellites. The Sentinel series of satellites is part of Copernicus programme designed by the European Union (EU) and European Space Agency (ESA). The all Sentinel 2 images (Level 1C) covering the entire study area were downloaded from the ESA's Sentinel Scientific Hub (ESA, 2018) [13] and the Landsat images were downloaded from the official site Landsat https://earthexplorer.usgs.gov/.

Launched in June 2015 for Sentinel 2A and in March 2017 for Sentinel-2B, these satellites are equipped with the optical instrument MSI (Multi-Spectral instrument), which covers 13 spectral bands from the visible through infrared. The Sentinel-2 mission is the continuation of programs Landsat and SPOT. These two satellites are able to provide images with a width at the ground of $290 \mathrm{~km}$, and a periodicity of 5 days. Acquisitions are carried out according to three resolutions in function of the spectral band: 10, 20 and $60 \mathrm{~m}$ (Table 2).

Table 1. Satellite data set available.

\begin{tabular}{ccc}
\hline Number & Date & Satellite \\
\hline 1 & $05 / 26 / 2018$ & Sentinel 2 \\
2 & $06 / 20 / 2018$ & Sentinel 2 \\
3 & $07 / 05 / 2018$ & Sentinel 2 \\
4 & $11 / 02 / 2018$ & Sentinel 2 \\
5 & $12 / 17 / 2017$ & Sentinel 2 \\
6 & $09 / 17 / 2017$ & Landsat 8 \\
7 & $07 / 30 / 2017$ & Sentinel 2 \\
8 & $04 / 21 / 2017$ & Sentinel 2 \\
9 & $06 / 15 / 2016$ & Sentinel 2 \\
10 & $04 / 23 / 2016$ & Landsat 8 \\
\hline
\end{tabular}

Table 2. Spatial and spectral resolutions of the Sentinel-2 satellite.

\begin{tabular}{cccc}
\hline Sentinel-2 Bands & Central Wavelength $(\mu \mathrm{m})$ & Resolution $(\mathrm{m})$ & Bandwidth $(\mathrm{nm})$ \\
\hline Band 1-Coastal aerosol & 0.443 & 60 & 20 \\
Band 2-Blue & 0.49 & 10 & 65 \\
Band 3-Green & 0.56 & 10 & 35 \\
Band 4-Red & 0.665 & 10 & 30 \\
Band 5-Vegetation Red Edge & 0.705 & 20 & 15 \\
Band 6-Vegetation Red Edge & 0.74 & 20 & 15 \\
Band 7-Vegetation Red Edge & 0.783 & 20 & 20 \\
Band 8-Near Infrared (NIR) & 0.842 & 10 & 115 \\
Band 8A-Narrow NIR & 0.865 & 20 & 20 \\
Band 9-Water vapor & 0.945 & 60 & 20 \\
Band 10-SWIR-Cirrus & 1.375 & 60 & 20 \\
Band 11-SWIR 1 & 1.61 & 20 & 90 \\
Band 12-SWIR 2 & 2.19 & 20 & 180 \\
\hline
\end{tabular}


Landsat 8, originally known as the Landsat Data Continuity Mission (LDCM), is a National Aeronautics and Space Administration (NASA)-US satellite. The conception of LDCM to the reality of Landsat 8 followed an arduous path extending over nearly 13 years, but the successful launch on February 11, 2013 ensures the continuity of the unparalleled Landsat record. Access to Landsat 8 data was opened to users worldwide. With a mission objective to enable the detection and characterization of global land changes at a scale where differentiation between natural and human-induced causes of change is possible, LDCM promised incremental technical improvements in capabilities needed for Landsat scientific and applications investigations [14]. The Landsat 8 satellite carries a two-sensor payload, the Operational Land Imager (OLI) and the Thermal Infrared Sensor (TIRS). The OLI and TIRS spectral bands remain broadly comparable to the Landsat 7 Enhanced Thematic Mapper plus (ETM+) bands. Compared to the ETM+, the OLI has two additional reflective wavelength bands: a new shorter wavelength blue band $(0.43-0.45 \mu \mathrm{m})$ intended for improved sensitivity to chlorophyll and other suspended materials in coastal waters and for retrieving atmospheric aerosol properties, and a new shortwave infrared band (1.36 - $1.39 \mu \mathrm{m})$ for cirrus cloud detection. The other OLI bands are spectrally narrower in most cases than the corresponding ETM+ bands [15] (Table 3).

We linked the shooting dates of the satellite images available for our study with the main cultivation stages of rice in the Red River Delta. Generally speaking there are two main harvests per year in the Red River Delta, thus two harvest seasons: the spring-summer season (from February to July) and the autumn-winter season (from August to January). The first stage concerns the preparations taking place in the rice fields: from mid-January onwards, with the harvest taking place 100 days later, at the end of April/May. The second stage is the soil preparations after the first harvest from the end of May onwards, thus the $2^{\text {nd }}$ stage

Table 3. Spatial and spectral resolutions of the Landsat 8 satellite.

\begin{tabular}{|c|c|c|c|}
\hline & Bands & $\begin{array}{l}\text { Wavelength } \\
\text { (micrometers) }\end{array}$ & $\begin{array}{c}\text { Resolution } \\
\text { (meters) }\end{array}$ \\
\hline & Band 1 -Coastal aerosol & $0.43-0.45$ & 30 \\
\hline & Band 2-Blue & $0.45-0.51$ & 30 \\
\hline & Band 3-Green & $0.53-0.59$ & 30 \\
\hline Landsat 8 Operational & Band 4-Red & $0.64-0.67$ & 30 \\
\hline $\begin{array}{c}\text { Land Imager (OLI) } \\
\text { And Thermal Infrared }\end{array}$ & Band 5-Near infrared (NIR) & $0.85-0.88$ & 30 \\
\hline Sensor (TIRS) & Band 6-SWIR 1 & $1.57-165$ & 30 \\
\hline Launched & Band 7-SWIR 2 & $2.11-2.29$ & 30 \\
\hline \multirow[t]{4}{*}{ February 11, 2013} & Band 8-Panachromatique & $0.50-0.68$ & 15 \\
\hline & Band 9-Cirrus & $1.36-1.38$ & 30 \\
\hline & Band 10-Thermal infrared (TIRS) 1 & $10.60-11.19$ & 100 \\
\hline & Band 11-Thermal infrared (TIRS) 2 & $11.50-12.51$ & 100 \\
\hline
\end{tabular}


occurs until the end of August/beginning of September. From September to mid-January vegetables are grown (Table 4 and Table 5).

\section{Methodology}

The methodology deals with the processing and analysis of Sentinel-2 and Landsat-8 satellite imagery (Figure 2). The methodology chosen is the application of GEOBIA image analysis in combination with the Sentinel-2 and Landsat-8 time series stacking.

The first step of image processing was the NDVI calculation the vegetation index using Sentinel-2 and Landsat- 8 images. A vegetation index can be an indicator to describe the greenness, density and health of vegetation. Vegetation indices were calculated for the Sentinel-2A reflectance image: NDVI (Normalized Difference Vegetation Index [16]. NDVI is a commonly used vegetation index in remote sensing. This index is defined by the reflectance of red (RED) band and near infrared (NIR) band since they sense very different depths through vegetation canopies. RED channel locates in the strong chlorophyll absorption region while NIR channel has high vegetation canopy reflectance in this area.

Vegetation index for Sentinel-2

$$
\mathrm{NDVI}=\frac{\mathrm{NIR}-\mathrm{RED}}{\mathrm{NIR}+\mathrm{RED}}=\frac{\mathrm{B} 8-\mathrm{B} 4}{\mathrm{~B} 8+\mathrm{B} 4}
$$

Table 4. Calendar of the rice in the area of the coast of the Red River delta.

\begin{tabular}{ccccc}
\hline Crop Season & Period & Planting Crops & Growth & Harvest \\
\hline \multirow{2}{*}{ Spring-Summer } & Early Harvest & $12 / 25-12 / 30$ & $02 / 05-02 / 10$ & $05 / 20-05 / 25$ \\
& Annual Harvest & $01 / 05-01 / 20$ & $02 / 20-02 / 25$ & $06 / 01-06 / 15$ \\
& Late Harvest & $02 / 25-03 / 05$ & $01 / 25-02 / 05$ & $06 / 25-06 / 30$ \\
& Early Harvest & $05 / 20-05 / 30$ & $06 / 01-06 / 10$ & $09 / 01-09 / 10$ \\
Autumn-Winter & Annual Harvest & $06 / 01-06 / 10$ & $06 / 10-06 / 20$ & $10 / 25-11 / 10$ \\
& Late Harvest & $06 / 25-07 / 05$ & $06 / 25-07 / 05$ & $11 / 05-11 / 25$ \\
\hline
\end{tabular}

Table 5. Crops of rice and passages of the Satellites.

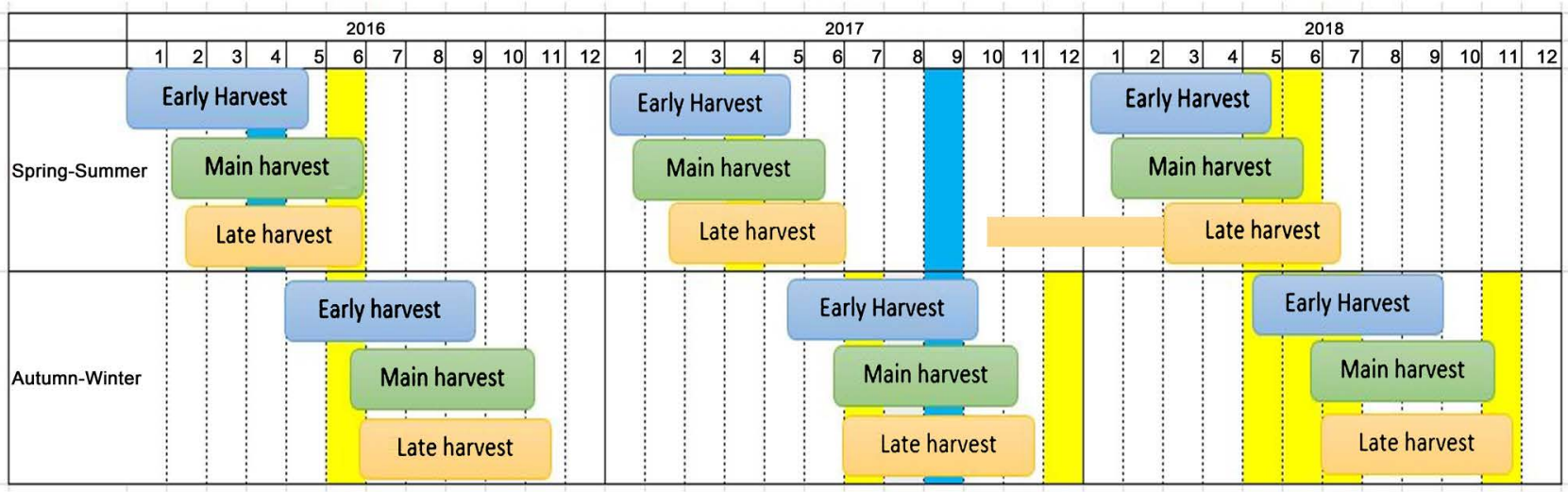




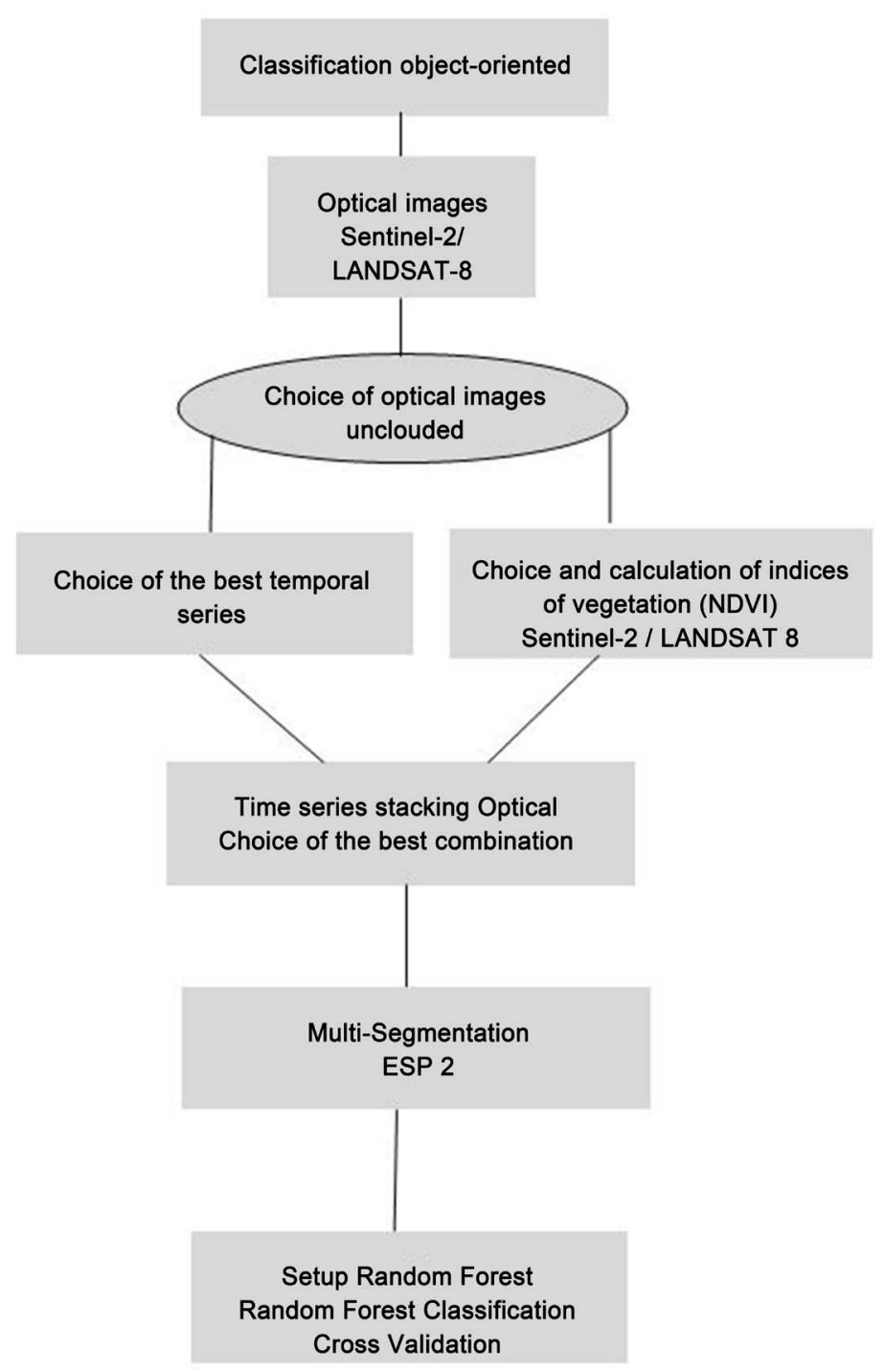

Figure 2. Pre-processing and processing chain.

Vegetation index for Landsat 8

$$
\mathrm{NDVI}=\frac{\mathrm{NIR}-\mathrm{RED}}{\mathrm{NIR}+\mathrm{RED}}=\frac{\mathrm{B} 5-\mathrm{B} 4}{\mathrm{~B} 5+\mathrm{B} 4}
$$

After layer normalization to same value range, layer stacking was performed by adding all the processed optical image layers. The following image layers were stacked into a 10-layers image for 2016: Sentinel-2A reflectance bands $(4 \times 2=8$ bands); Sentinel-2A NDVI ( 2 bands); Total $2016=10$ bands; Image 2017: Sentinel-2A reflectance bands $(4 \times 3=12$ bands; Landsat- 8 reflectance bands ( 4 bands); Sentinel-2A NDVI (3 bands); Landsat-8 NDVI (1 band); Total $2017=20$ bands. 2018 image: Sentinel $2 \mathrm{~A}$ reflectance bands $(4 \times 4=16$ bands); Sentinel $2 \mathrm{~A}$ NDVI $(1 \times 4=4$ bands $)$; Total $2018=20$ bands.

An important step in image processing was the multi segmentation of images using the new Estimation of Scale Parameter (ESP2) tool. Multiscalar image segmentation is a fundamental step in GEOBIA, yet there is currently no tool 
available to objectively guide the selection of appropriate scales for segmentation, with the exception of the Estimation of Scale Parameter (ESP2) tool (Figure 3).

The ESP tool allows for a fast estimation of scale parameters for a multiresolution segmentation in the Definiens software environment. Segmentation is the process of dividing remotely sensed images into discrete regions or objects that are homogeneous with regard to spatial or spectral characteristics [17]. This tool, called estimation of scale parameter (ESP), analyzes the local variance (LV) of object heterogeneity of the satellite images. What "suitable" means depends primarily on how scale is conceptualized: as an inherent property of phenomena and their associated physical entities (and implicitly of their digital representations), or as a "window of perception" [4]. Building on the results of Kim et al. (2008) [18], we used the concept of LV [19] to create a tool that informs suitable scale parameter selection for segmentation in Definiens Developer. The ESP tool iteratively generates image-objects at multiple scale levels in a bottom-up approach and calculates the LV for each scale. Variation in heterogeneity is explored by evaluating LV plotted against the corresponding scale. The thresholds in rates of change of LV (ROC-LV) indicate the scale levels at which the image can be segmented in the most appropriate manner, relative to the data properties at the scene level [20]. The ESP tool is programmed in Cognition Network Language $(\mathrm{CNL})$ in the Definiens Developer software, a modular programming language for OBIA applications [21]. It is implemented as a customized process to be applied easily like other processes in object-based rule set creation in the Definiens software. Six user defined parameters are used: 1) step size of the

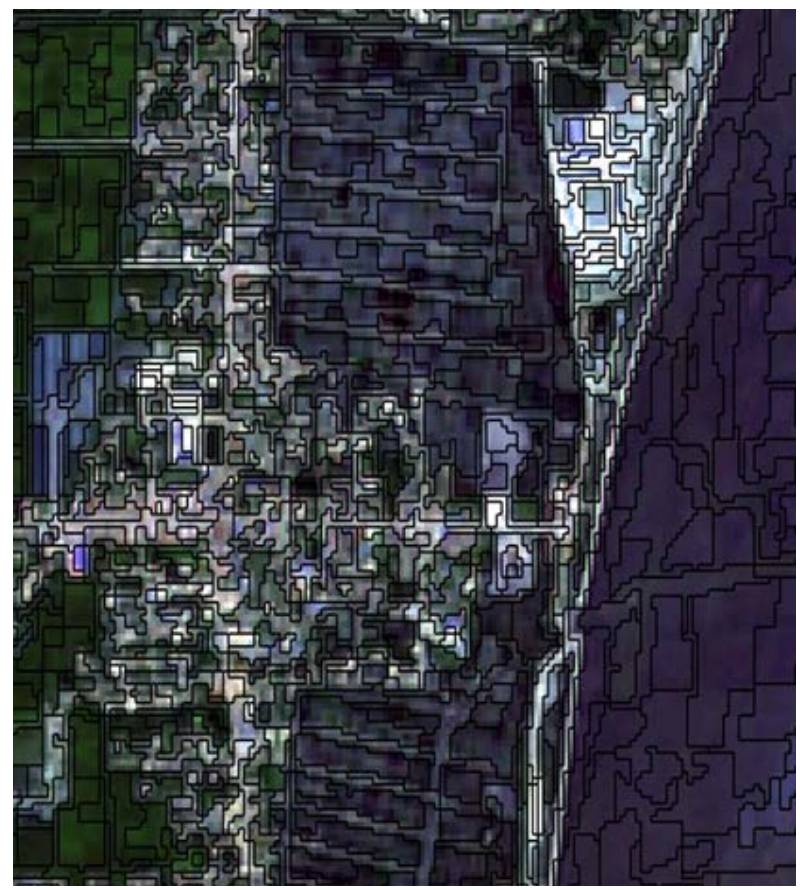

Figure 3. Segmentation ESP2. Parameter of segmentation: scale 20; shape 0.05; compactness 0.1 ; ponderation of the bands of visible: 1 ; ponderation of the bands NDVI: 2 . 
increasing scale parameter, 2) starting scale parameter for the analysis, 3) the use of an object hierarchy during segmentation, 4) number of loops, 5) shape weighting, and 6) compactness weighting. Parameters 2), 5), and 6) are used as implemented in the multiresolution segmentation [20] and described by Baatz and Schäpe (2000) [22] and Benz et al. (2004) [23].

The algorithm chosen for the supervised classification is the Random Forest. Random Forests (RF) of Breiman [24] is a well-known ensemble learning method that combines $\mathrm{K}$ binary CART trees (Classification and Regression Trees) [25]. Random Forest is based on tree classifiers. The random forests algorithm trains a number of trees on slightly different subsets of data (bootstrap sample), in which a case is added to each subset containing random selections from the range of each variable. This group of trees is similar to an ensemble. Each decision tree in the ensemble votes for the classification of each input case. Random forests are a collection of decision trees aimed to be an improvement in performance over single decision trees. A random forest is constructed by generating decision trees for sub samples of the data. Decision trees are the building blocks of random forests. Hence, training and classification times for a single decision tree are lower compared to random forests with multiple trees (Figure 4).

Classifying is then performed much in the same way as with regular decision trees, where the resulting class is the mean class of all the single decision trees in the forest. The trees in a random forest are generated in a way that attempts to split the data set at every node in half. For both halves, this algorithm is repeated until every leaf in the tree contains only one sample. Contrary to classical Decision Trees (DT), the RF trees are built without pruning and by randomly selecting at each node a subset of input variables. Currently, this number of variables used to split a RF node (denoted by $\mathrm{m}$ ) corresponds to the square root of the number of input variables [26]. The corresponding parameters for the Random Forest Classifier class are as follows: max_depth controls the amount of layers of the tree. A subset of variables (the number of which is represented by the term $\mathrm{m}$ ) is chosen, being much less than the number of variables, and the best split is determined on this subset of variables. The number of variables used in the

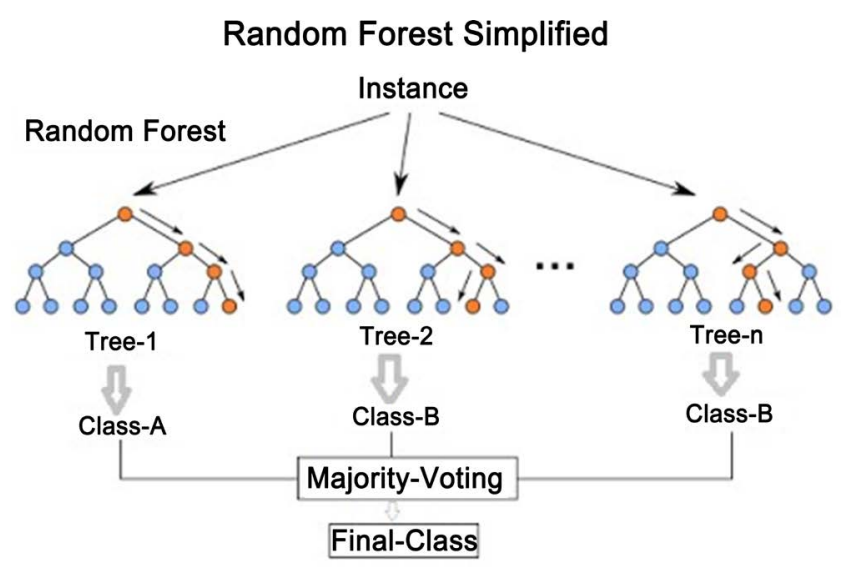

Figure 4. Performance of the random forest algorithm. 
algorithm determines the classification accuracy. The more variables we use the more the correlations between decision trees and the more the classification accuracy (less misclassified pixels). Decreasing $\mathrm{m}$ decreases the correlation between classification trees but will be less accurate or its predictive power diminishes. The Random Forest is a very useful approach, it is not only nonparametric but it also provides a way of estimating the importance of the individual variables in classification. In ensemble classification, several classifiers are trained and their results combined through a voting process. Many ensemble methods have been proposed. Most widely used such methods are boosting and bagging [27]. Among many advantages of Random Forest the significant ones are: unparalleled accuracy among current algorithms, efficient implementation on large data sets, and an easily saved structure for future use of pre-generated trees [15].

In this work, the setting used for Random Forest was: Maximum depth of the tree (25), Minimum number of sample in each node (50) and Cluster possible values of a categorical variable into $\mathrm{k}(\mathrm{k}=8)$.

\section{Results and Discussion}

The methodological objective of this study was to evaluate the performance of Random Forest method when applied to land cover/land use mapping from Sentinel- 2 and Landsat- 8 time-series data. The methodology and the algorithm were used to improve the accuracy of recognition and mapping of land cover/land use in Red River Delta in Vietnam. A set of land cover/land use categories of interest were defined, namely: aquaculture, mangroves, rice, vegetables, villages, water and wetland (Figure 5).

In terms of the distribution of land use categories in the district, the agricultural fields (rice paddies) located inside the dikes cover more than $40 \%$ of the total surface area during the three years of observation. Water covers about $23 \%$ to $28 \%$ of the surface area and is mainly represented by the sea, the Red River and the rivers Lân and Tra Ly. Villages including gardens, cover approximately $14 \%$ to $15 \%$ and are located in the midst of the rice paddies. Wet soils are not really

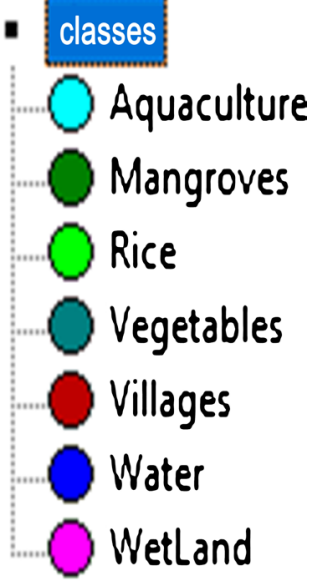

Figure 5. Land use/land cover classes. 
found inside the dikes, except at the edge of the irrigation canals, but rather on the outside of the dikes, at the mouths of the Tra Ly River in the north and the Red River in the south of the district. Aquaculture ponds are often located outside the dikes but sometimes within the dikes and the percentage surface area occupied by it did not change in 2016 but increased by about $5 \%$ in 2017 and $8 \%$ in 2018. On the other hand, mangroves were found on the islands in the estuaries of these same rivers during 2016, but they have become very sparse by 2018. In 2018, new mangroves were planted around the aquaculture ponds. Submerged shrubs are scattered outside the dikes and sometimes within the dikes, covering about $1 \%$ to $3 \%$ of the area. Nuts edge and vegetables in general are often found in the lowlands near the banks of the Red River. Lastly, salt marshes cover very little territory, mostly in the center of the district and next to the dikes.

The results show very good classification performance for all combinations (kappa index 0.90 and 0.97). Following standard accuracy calculation procedures [28] (Congalton \& Green, 2009), we estimated an overall accuracy of 93\% (2016), 97\% (2017) and 98\% (2018) and a Kappa coefficient of 0.90 (2016) and 0.97 (2017 and 2018). Omission and commission classification errors were found mainly in "vegetables" class for 2016 and in "wetland" class for the three years (Table 6). The wetlands are confused with the aquaculture. Particularly in Asia, aquaculture ponds are dominant near river deltas and estuaries where paddy cultivation is also a major practice. The temporary flooding of fields during the paddy growing season and shape characteristics similar to aquaculture ponds can create significant misclassification between these types when unitemporal approaches are applied. A dense time series of Sentinel- 2 and Landsat- 8 acquisition can help to distinguish between temporarily flooded water bodies from relatively stable flooded aquaculture ponds.

Looking at the changes by stellite images (Figure 6) in the municipalities in the Tien Hai District that have different physical characteristics, the following

Table 6. Overall accuracy and kappa index by class for the random forests classifications.

\begin{tabular}{cccc}
\hline Land cover classes & $\begin{array}{c}\text { Accuracy (\%) } \\
\text { optic + NDVI 2018 }\end{array}$ & $\begin{array}{c}\text { Accuracy (\%) } \\
\text { optic + NDVI 2017 }\end{array}$ & $\begin{array}{c}\text { Accuracy (\%) } \\
\text { optic + NDVI 2016 }\end{array}$ \\
\hline Rice & 99 & 100 & 97 \\
Villages & 100 & 100 & 100 \\
Water & 100 & 100 & 94 \\
Mangroves & 100 & 100 & 100 \\
Aquaculture & 95 & 95 & 99 \\
Vegetables & 93 & 91 & 47 \\
Wetland & 76 & 81 & 71 \\
Kappa index & $\mathbf{0 . 9 7}$ & $\mathbf{0 . 9 7}$ & $\mathbf{0 . 9 0}$ \\
Overall accuracy & $\mathbf{0 . 9 8}$ & $\mathbf{0 . 9 7}$ & $\mathbf{0 . 9 3}$ \\
\hline
\end{tabular}



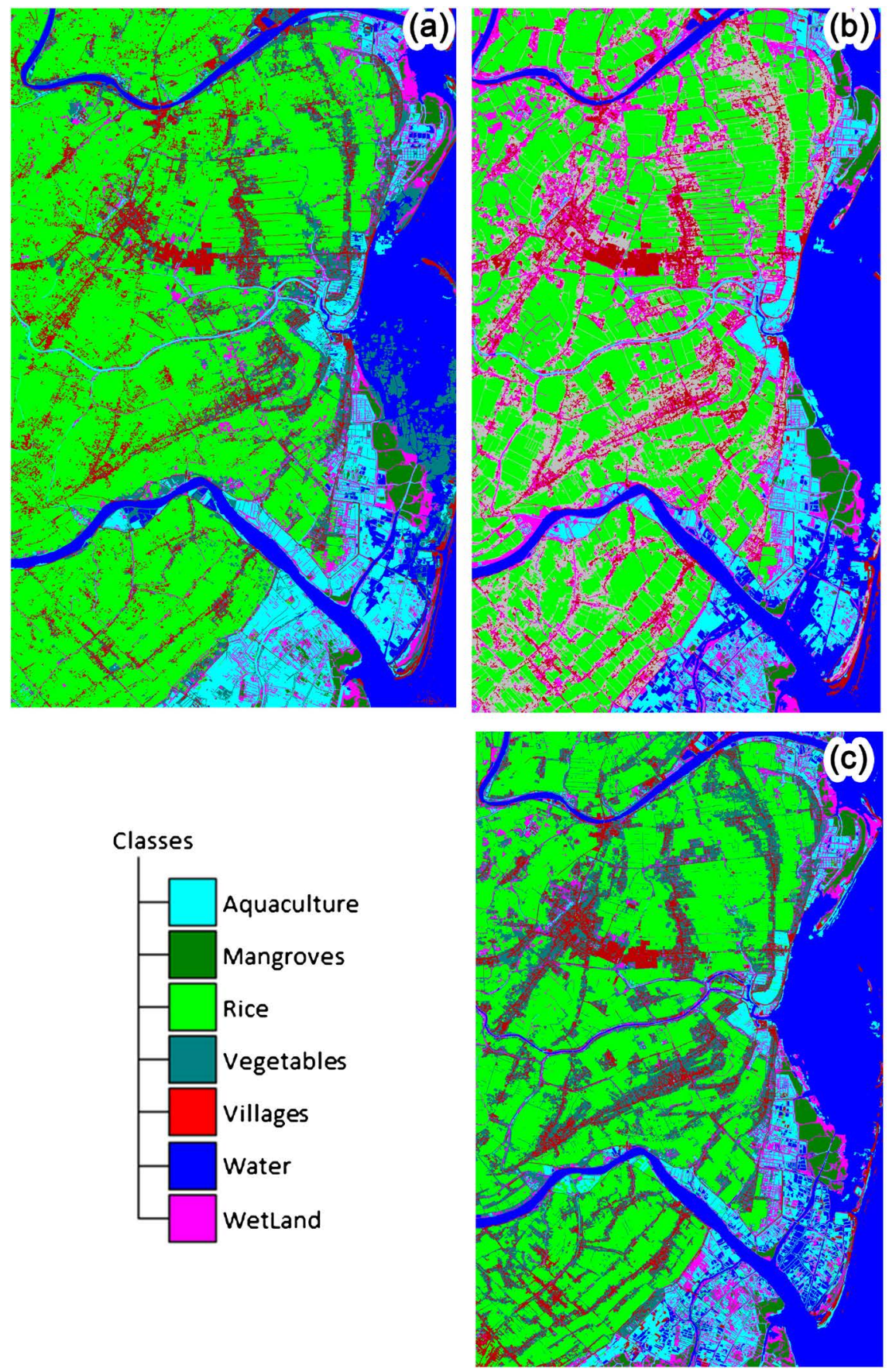

Figure 6. Random Forest Classification by Time series stacking of Sentinel-1 and Landsat 8 images (a) 2016; (b) 2017; (c) 2018.

comments can be made:

- municipalities with the same biophysical conditions (such as Nam Phu and Dong Long) displayed several similar trends in changed land-use due to the fact that they have the same coastal ecosystems; what is more, their differences are often caused by human activities: the recent foundation of Nam Phu contributing to the expansion of its agricultural fields, the hasty commencement of Nam Phu aquaculture encouraging the development of ponds 
and the significant cutting down of mangroves; the second had such a pivotal impact on changes in the surface area of aquaculture ponds and mangroves that one could not see the differences caused by environmental protection regulations in the Nam Phu Nature Reserve;

- municipalities with different biophysical conditions (such as Tây Tiên and the Dong Long municipalities) do not have the same types of land use; they have only two similarities: villages and agricultural fields that are inside the dikes and which do not vary much; the other land use types differ greatly in terms of surface area; there are only two types of land use in Dông Long that are not found in Tây Tiên, namely the nutsedge fields and aquaculture.

Physical and anthropogenic factors do not have the same impact on changes in land use. In addition, we note that, despite the intermingling of image processing that must be improved, the detection of land use changes with the help of satellite images is very useful. We were able to see how each type of land use has changed in the district during the years under observation to explain the relationship between economic liberalization and land use changes. These changes reflect the impact of physical factors (such as the characteristics of the coastal ecosystems that favor mangroves, submerged shrubs, salt marshes and aquaculture production) and anthropogenic factors (economic liberalization, the new policy of stimulating aquaculture and economic development plans by the government) on land use. Anthropogenic factors have a greater impact on changes than physical factors, especially in the rapid increase in aquaculture ponds, which in turn brought about changes in other types of land use. The increased demand for shrimp has also influenced other types of land use at Tiên Hai, namely the replacement of salt marshes and rice fields with aquaculture ponds. The reality is that, instead of earning only 10 million VND (Vietnamese currency) per hectare of rice, farmers can get 114 million VND for one hectare of shrimp ponds. This means that with shrimp production they can earn ten times more than with the production of salt or rice. As a result, 380 ha of salt marshes were changed to aquaculture ponds, increasing surface area occupied by aquaculture in the district to 1000 ha [29].

\section{Conclusions}

Despite some limitations, the image processing performed in this study is suitable for Vietnam's highly fragmented and dynamic coastal area thanks to its effectiveness in detecting changes in land use and in identifying the categories themselves. The image processing shows the environmental degradation due to land-use changes, including mangrove cutting and the disappearance of rice paddies and salt marshes, as well as the pollution of aquaculture ponds.

Geographic Object-Oriented (GEOBIA) concepts and methods have been successfully applied to study of changes land cover in Red river delta, district of Tien Hai. The emerging trends were found in multiple sub fields of GEOBIA, including data sources, image segmentation, object-based feature extraction, and 
geo-object-based modeling frameworks. Segmentation is the partitioning of an array of measurements on the basis of homogeneity. It divides an image-or any raster or point data-into spatially continuous, disjointed and homogeneous regions referred to as "segments". In feature extraction, it can be regarded as an end in itself. In GEOBIA, it is one step in a processing chain to ultimately derive "meaningful objects". A very important concept to distinguish GEOBIA from per-pixel approaches is the ability to address a multiplicity of scales within one image and across several images. The ESP2 tool was used to select a parameter which is unique to the landscape structures. The image object is classified with machine learning methods (such as random forests) based on semantic network model and hybrid (top-down, bottom-up) control tactics.

In view of the rapid development of the global changes of coastal zone, with all its positive and negative effects on prevailing socio-ecological systems, the demonstrated low cost approach based on open source data is of high relevance to all aspects, i.e. planning, decision making, management, and monitoring, of an integrated and sustainable management of the coastal zone.

\section{Conflicts of Interest}

The authors declare no conflicts of interest regarding the publication of this paper.

\section{References}

[1] Amit, K.B., Carsten, O., Jurgen, S., Murodjon, S. and Olena, D. (2017) Towards Improved Land Use Mapping of Irrigated Croplands: Performance Assessment of Different Image Classification Algorithms and Approaches. European Journal of Remote Sensing, 50, 187-201. https://doi.org/10.1080/22797254.2017.1308235

[2] Blaschke, T. (2010) Object Based Image Analysis for Remote Sensing. ISPRS Journal of Photogrammetry and Remote Sensing, 65, 2-16.

https://doi.org/10.1016/j.isprsjprs.2009.06.004

[3] Chen, G., Weng, Q.H., Hay, G.J. and He Y. (2018) Geographic Object-Based Image Analysis (GEOBIA): Emerging Trends and Future Opportunities. GIScience \& Remote Sensing, 55, 159-182. https://doi.org/10.1080/15481603.2018.1426092

[4] Marceau, D., Howarth, P.J., Dubois, J.M. and Gratton, D.J. (1990) Evaluation of the Grey-Level Co-Occurrence Matrix Method for Land-Cover Classification Using SPOT Imagery. IEEE Transactions on Geoscience and Remote Sensing, 28, 513-519. https://doi.org/10.1109/TGRS.1990.572937

[5] Hay, G.J. and Niemann, K.O. (1994) Visualizing 3-D Texture: A Three-Dimensional Structural Approach to Model Forest Texture. Canadian Journal of Remote Sensing, 20, 90-101.

[6] Hay, G.J., Niemann, K.O. and Goodenough, D.G. (1997) Spatial Thresholds, Image-Objects, and Upscaling: A Multiscale Evaluation. Remote Sensing of Environment, 62, 1-19. https://doi.org/10.1016/S0034-4257(97)81622-7

[7] Hay, G.J. and Castilla, G. (2008) Geographic Object-Based Image Analysis (GEOBIA): A New Name for a New Discipline. In: Blaschke, T., Lang, S. and Hay, G., Eds., Object-Based Image Analysis: Spatial Concepts for Knowledge-Driven Remote Sensing Applications, Lecture Notes in Geoinformation and Cartography, 
Springer, Berlin, Heidelberg, 75-89.

[8] Blaschke, T., Hay, G.J., Kelly, M., Lang, S., Hofmann, P., Addink, E., Queiroz Feitosa, R., van der Meer, F., van der Werff, H., van Coillie, F. and Tiede, D. (2014) Geographic Object-Based Image Analysis-Towards a New Paradigm. ISPRS Journal of Photogrammetry and Remote Sensing, 87, 180-191.

https://doi.org/10.1016/j.isprsjprs.2013.09.014

[9] Baatz, M., Hoffmann, C. and Willhauck, G. (2008) Progressing from Object-Based to Object-Oriented Image Analysis. In: Blaschke, T., Lang, S. and Hay, G.J., Eds., Object-Based Image Analysis. Spatial Concepts for Knowledge-Driven Remote Sensing Applications, 1st Edition, Springer, Berlin, Heidelberg, 29-42.

[10] Wężyk, P., Hawryło, P., Szostak, M., Pierzchalski, M. and Kok, R.D. (2016) Using Geobia and Data Fusion Approach for Land use and Land Cover Mapping. Quaestiones Geographicae, 35, 93-104. https://doi.org/10.1515/quageo-2016-0009

[11] Bergeret, P. (2004) Les enjeux de la libéralisation économique pour le développement agricole au Vietnam, Dans Le Vietnam à l'aube du XXIe siècle: Bilan et perspectives politiques, économiques et sociales, Éditions Karthala. 353 p.

[12] Do, N.H. and Egashira, K. (2002) Irrigation and Drainage Systems and Their Impact on Land Use and Rice Production after Renovation (Doi Moi) in the Red River Delta of Vietnam-A Case Study in Tien Son District, Bac Ninh Province. Journal of the Faculty of Agriculture, Kyushu University, 46, 411-422.

[13] European Space Agency (2018) Sentinel Scientific Hub. https://scihub.copernicus.eu/dhus/\#/home

[14] Loveland, T.R. and Irons, J.R. (2016) Landsat 8: The Plans, the Reality, and the Legacy. Remote Sensing of Environment, 185, 1-6.

[15] Roy, D.P., Wulder, M.A., Loveland, T.R., C.e., W., Allen, R.G., Anderson, M.C., Helder, D., Irons, J.R., Johnson, D.M., Kennedy, R., Scambos, T.A., Schaaf, C.B., Schott, J.R., Sheng, Y., Vermote, E.F., Belward, A.S., Bindschadler, R., Cohen, W.B., Gao, F., Hipple, J.D., Hostert, P., Huntington, J., Justice, C.O., Kilic, A., Kovalskyy, V., Lee, Z.P., Lymburner, L., Masek, J.G., McCorkel, J., Shuai, Y., Trezza, R., Vogelmann, J., Wynne, R.H. and Zhu, Z. (2014) Landsat-8: Science and Product Vision for Terrestrial Global Change Research. Remote Sensing of Environment, 145, 154-172. https://doi.org/10.1016/j.rse.2014.02.001

[16] Rouse, J.W., Haas, R.H., Schell, J.A., Deering, D.W. and Harlan, J.C. (1974) Monitoring the Vernal Advancement and Retrogradation (Green Wave Effect) of Natural Vegetation. NASA/GSFC Type III Final Report, Greenbelt, MD, 371 p.

[17] Ryherd, S. and Woodcock, C. (1996) Combining Spectral and Texture Data in the Segmentation of Remotely Sensed Images. Photogrammetric Engineering \& Remote Sensing, 62, 181-194.

[18] Kim, M., Madden, M. and Warner, T. (2008) Estimation of Optimal Image Object Size for the Segmentation of Forest Stands with Multispectral IKONOS Imagery. In: Blaschke, T., Lang, S. and Hay, G.J., Eds., Object-Based Image Analysis: Spatial Concepts for Knowledge Driven Remote Sensing Applications, Springer, Berlin, 291-307. https://doi.org/10.1007/978-3-540-77058-9_16

[19] Woodcock, C. and Strahler, A. (1987) The Factor of Scale in Remote Sensing. Remote Sensing of Environment, 21, 311-332.

https://doi.org/10.1016/0034-4257(87)90015-0

[20] Drăgut,, L., Tiede, D. and Levick, S.R. (2010) ESP: A Tool to Estimate Scale Parameter for Multiresolution Image Segmentation of Remotely Sensed Data. International Journal of Geographical Information Science, 24, 859-871. 
https://doi.org/10.1080/13658810903174803

[21] Tiede, D. and Hoffmann, C. (2006) Process Oriented Object-Based Algorithms for Single Tree Detection Using Laser Scanning. In: Koukal, T. and Schneider, W., Eds., International Workshop 3D Remote Sensing in Forestry, Vienna, 162-167.

[22] Baatz, M. and Schäpe, A. (2000) Multiresolution Segmentation-An Optimization Approach for High Quality Multi-Scale Image Segmentation. In: Strobl, J., Blaschke, T. and Griesebner, G., Eds., Angewandte geographische informations verarbeitung, Wichmann-Verlag, Heidelberg, 12-23.

[23] Benz, U.C., Hofmann, P., Willhauck, G., Lingenfelder, I. and Heynen, M. (2004) Multi-Resolution, Object-Oriented Fuzzy Analysis of Remote Sensing Data for GIS-Ready Information. ISPRS Journal of Photogrammetry and Remote Sensing, 58, 239-258. https://doi.org/10.1016/j.isprsjprs.2003.10.002

[24] Breiman, L. (2001) Random Forests. Machine Learning, 45, 5-32. https://doi.org/10.1023/A:1010933404324

[25] Breiman, L., Friedman, J.H., Olshen, R.A. and Stone, C.J. (1984) Classification and Regression Trees. Wadsworth International Group, Belmont, CA.

[26] Liaw A. and Wiener M. (2002) Classification and Regression by Random Forest. $R$ News, 2, 18-22.

[27] Ghose, M.K., Ratika, P. and Sushan, G.S. (2010) Decision Tree Classification of Remotely Sensed Satellite Data Using Spectral Separability Matrix. International Journal of Advanced Computer Science and Applications, 1, 93-101.

[28] Congalton, R.G. and Green, K. (2009) Assessing the Accuracy of Remotely Sensed Data, Principles and Practices. 2nd Edition, CRC Press, Taylor \& Francis Group, London.

[29] SarDesai, D.R. (2018) Vietnam: Past and Present. Routledge, Abingdon-on-Thames. 